\title{
Acoustic Emission Test of Changlongshan Pumped Storage Power Station Steel Bifurcation Pipe
}

\author{
DING Peng ${ }^{1} *$, GUAN Lei ${ }^{1}$, QIU Congwei ${ }^{1}$, YANG Chuansheng $^{1}$, XU Ling ${ }^{1}$ \\ ${ }^{1}$ Standard \& Quality Control Research Institute Ministry of Water Resources.P.R.C, Hangzhou 310012, China
}

\begin{abstract}
The maximum test load of Changlongshan pumped storage power station steel bifurcation pipe is $10 \mathrm{MPa}$. To ensure the safety of the water pressure test, acoustic emission is used to monitor the main welds of the crescent rib steel bifurcation and main cone. Taking NO.3 pipe's data as an example, acoustic emission source location system was used to find the possible position of harmful defects, through the activity and intensity of the acoustic emission sources to confirm the defect significance. After analysis, the acoustic emission integrated level of the steel bifurcation pipe is in level II, the pipe's data comply with the design requirements.
\end{abstract}

\section{Introduction}

The Changlongshan pumped storage power station is located in Anji County, Zhejiang Province. It is located in the load center of the East China Power Grid. The design and installation scale is $2100 \mathrm{MW}(6 \times 350 \mathrm{MW})$. The power station hub is mainly composed of an upper reservoir, lower reservoir, water conveyance system, underground powerhouse, and switch station. After completion, it mainly undertakes the tasks of peakshaving, valley filling, frequency modulation, phase modulation, and emergency standby of East China Power Grid $^{[1]}$.

The power station hub is mainly composed of an upper reservoir, diversion system, underground powerhouse system, tailwater system, and lower reservoir project. The water diversion system adopts three holes and six machine inclined shaft arrangements. Along the flow direction, the upper reservoir inlet/outlet, the upper reservoir accident repair gate well, the diversion upper flat hole, the diversion upper inclined shaft, the diversion middle flat hole, the diversion lower inclined shaft, the diversion lower flat hole, the steel bifurcation pipe, the highpressure branch pipe section. Among them, the concrete lining is used in the upper flat hole, the upper inclined shaft, and the first half of the middle flat hole, and steel lining is used in the second half of the middle flat hole, the lower inclined shaft, the lower flat hole, the steel branch pipe, and the high-pressure branch pipe section.

The steel bifurcation pipe from the upstream side wall is $60 \mathrm{~m}$. There are three pipes. In the pipe,semmetry "Y" strengthening crescent rib type is used. The bifurcation angle is $75^{\circ}$, the main pipe diameter is $4.0 \mathrm{~m}$, the branch pipe diameter is $2.8 \mathrm{~m}$. The radius of common cutting ball of the steel bifurcated pipe is $2351.7 \mathrm{~mm}$. The material is
SX780CF high strength steel. The wall thickness of main and branch pipes is $66 \mathrm{~mm}$, and the wall thickness of crescent ribs is $138 \mathrm{~mm}$. The maximum shape size of the branch pipe is about $5.91 \times 6.97 \times 4.87 \mathrm{~m}$. The internal water head (water hammer pressure) is $1200 \mathrm{~m}$ $(11.77 \mathrm{MPa})$, The HD value is up to $4800 \mathrm{~m} \cdot \mathrm{m}$. Its size is first in the country, top of the world.

To ensure the product quality and ensure the safety of the test process, the Institute of Product quality Standards of the Ministry of Water Resources is entrusted with the work of stress, acoustic emission, and other related inspection and testing in the hydraulic test process of three steel forks.

\section{Basic principles of acoustic emission}

Acoustic emission (AE) refers to the transient elastic wave phenomenon caused by the rapid release of local source energy in the material ${ }^{[2-5]}$. The typical acoustic emission source is related to the deformation process, and cracks, defect propagation and elastic deformation of materials will produce acoustic emission signals. The process of generating and detecting acoustic emission signals is shown in figure 1 . The acoustic emission source mutates to produce an elastic wave, which propagates to the whole structure, and causes the sensor on the surface to produce resonance and receive the acoustic emission signal. when the material stress increases, the generated acoustic emission signal increases. One or more sensors on the surface receive the signal and amplify and filter to generate acoustic emission data and display. 


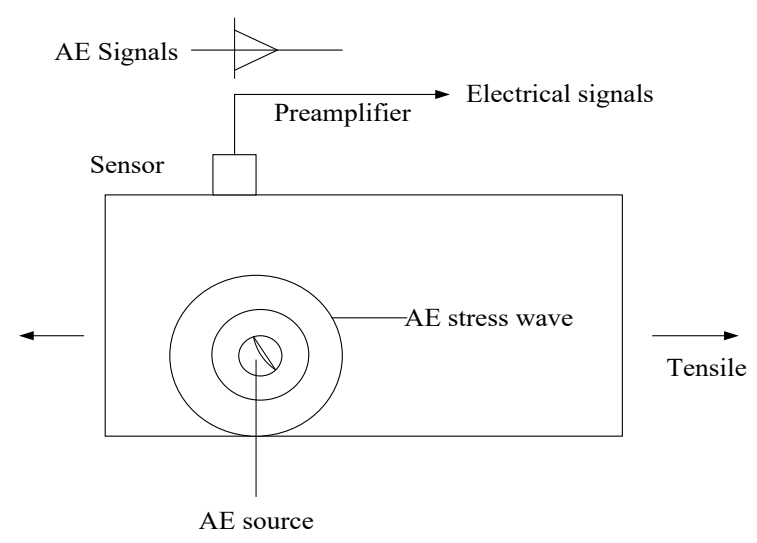

Figure 1. Basic principles of acoustic emission

The energy source of acoustic emission refers to the elastic stress field inside the material ${ }^{[6-10]}$. No acoustic emission will occur without stress. Therefore, acoustic emission detection is generally carried out in the case of controllable applied stresses on materials, which include all load experimental stresses such as standard loads before use, controllable variable loads used in service, gradient stress experiments, fatigue tests, and load tests. The hydraulic test of the steel branch pipe is the controllable external force applied to the branch pipe. The welding quality of the branch pipe can be evaluated comprehensively by using acoustic emission to monitor the acoustic emission during the application of the branch pipe.

\section{Hydraulic test of steel fork pipe}

\subsection{Location of survey points}

The signal acquisition and positioning mode of weld emission monitoring of crescent rib and cone tube adopt plane positioning. Seven sensors are arranged at $20 \mathrm{~cm}$ on both sides of the crescent rib weld ( 3 on one side and 4 staggered on the other side), each sensor spacing is about

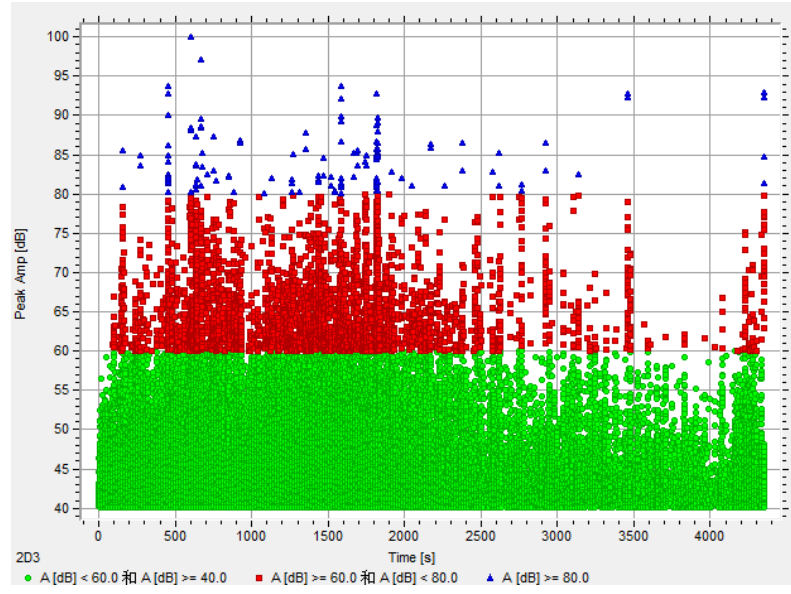

(a) Amplitude-Time Course Map
$1.7 \mathrm{~m}$, and one sensor is arranged at each end of the crescent rib. A sensor is arranged up and down $1.5 \mathrm{~m}$.

The signal acquisition and positioning model of the main cone circumferential weld emission monitoring adopt cylindrical positioning. The main cone and the upstream transition cone circumferential weld upstream side $20 \mathrm{~cm}$ circumferential arrangement 7 sensors, each sensor spacing about $1.8 \mathrm{~m}$; The main cone and the downstream pipe joint circumferential weld downstream side circumferential arrangement 8 sensors, each sensor spacing about $1.8 \mathrm{~m}$.

\subsection{Acoustic emission monitoring}

Hydraulic test prepress to 2.0MPa, Steady $30 \mathrm{~min}$; Boost to $4.0 \mathrm{MPa}$, Steady $30 \mathrm{~min}$; Down to $2.0 \mathrm{MPa}$, Steady 30 min; Down to 0.0MPa; Boost to 4.0MPa, Steady $30 \mathrm{~min}$; Boost to 6.0MPa, Steady 60min; Boost to $8.0 \mathrm{MPa}$, Steady $60 \mathrm{~min}$; Boost to $9.0 \mathrm{MPa}$, Steady $60 \mathrm{~min}$; Boost to $10.0 \mathrm{MPa}$, Steady pressure $60 \mathrm{~min}$ to boost and maintain pressure, monitoring the acoustic emission source in the process of boost and pressure keeping. The acoustic emission monitoring equipment adopts the AMSY-6 acoustic emission acquisition system of the German Vallen Company. The sensor model is VS 150-RIC (34 $\mathrm{dB})$. Channel sensitivity tests and acoustic attenuation tests are carried out before the test to ensure the accurate location of the acoustic emission source. Test the background noise before pressing, To eliminate the impact of the environment on acoustic emission.

\subsection{Monitoring results}

An acoustic emission acquisition system is used to monitor the pressure raising and holding process of hydraulic tests. Acoustic emission signals of each boost and pressure holding stage are analyzed, in which the acoustic emission parameters of $9 \mathrm{MPa}$ boost and pressure holding process are shown in figure 2.

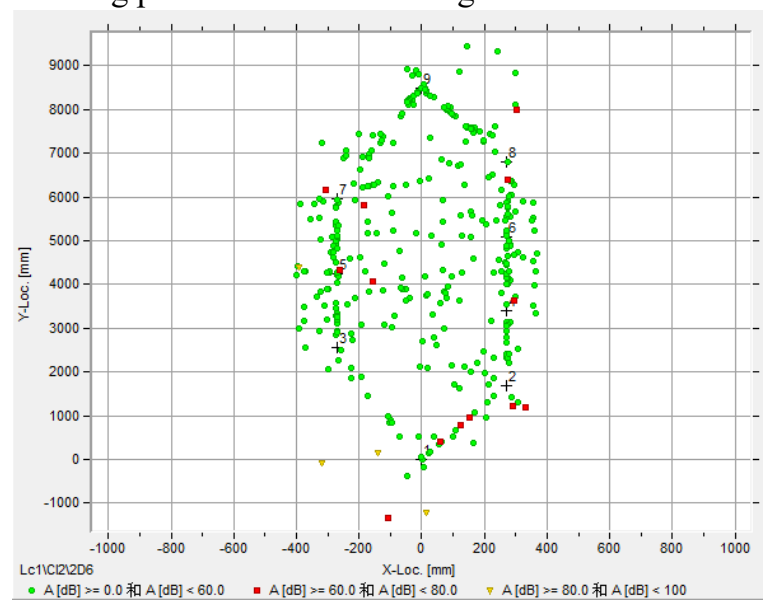

(b) Location map of crescent rib weld 


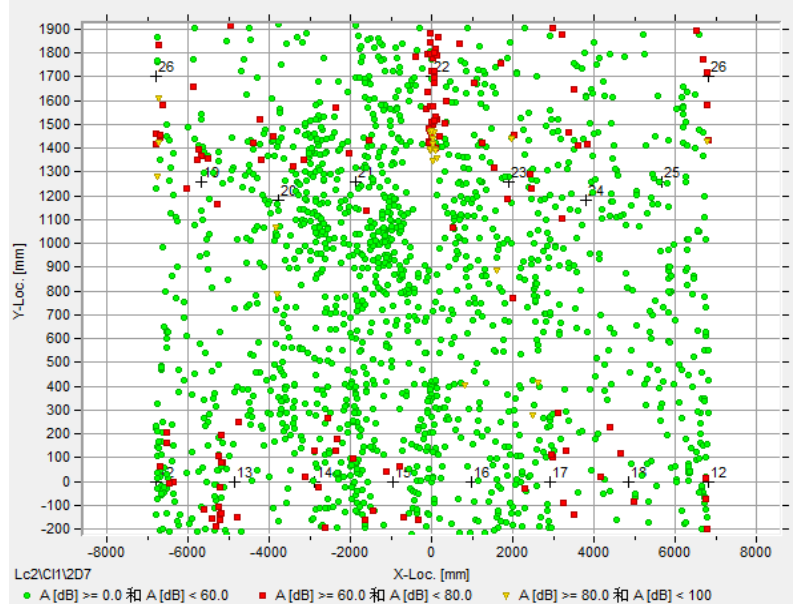

(c) Main cone circumferential weld orientation map

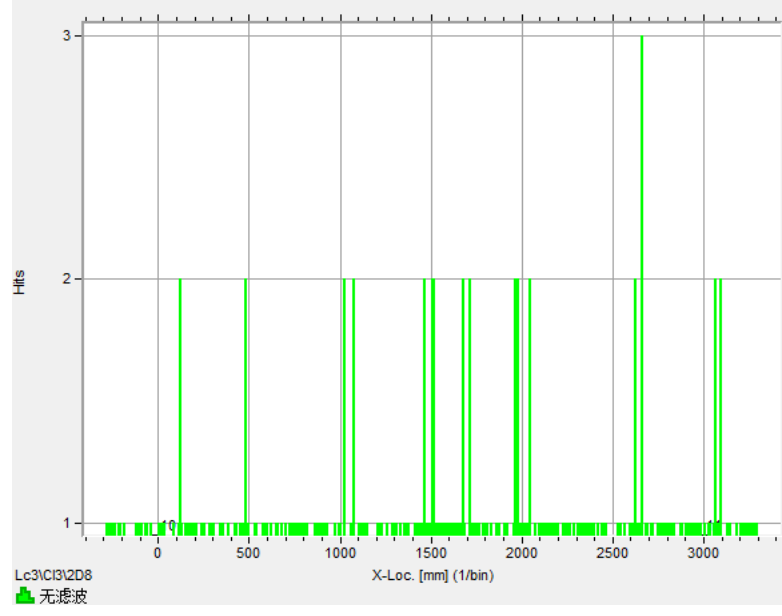

(d) Lumbar line location map of crescent ribs

Figure 2. Acoustic Emission Parameter Diagram of $9 \mathrm{MPa}$ Boost and Hold Pressure Process

As can be seen from Fig .2, near the 22\# sensor, that is, the intersection of the crescent rib with the supervisor and branch pipe, the sound emission location source with good amplitude appears several times.

The first pressurized cycle is separated from the second pressurized cycle for about 10 hours for two independent pressurized cycles. For the new container, after the first loading and pressing cycle is completed, the noise caused by friction between partial metal support and branch pipe wall, cracking, and shedding of oxide skin can be eliminated. At the same time, the hydraulic test equilibrates the stress at the tip of the steel bifurcation pipe

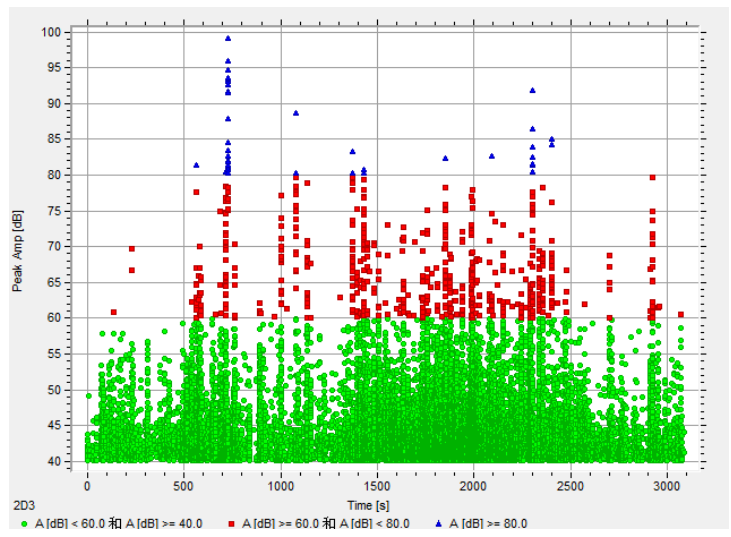

(a) Amplitude-Time Course Map and passives the pointed defect and releases the stress wave by elastic energy. For the second loading and pressing cycle, the effect of this kind of elastic wave on the useful acoustic emission signal produced by crack expansion becomes smaller, which is convenient for the screening and extraction of useful signals. According to the Kessel effect of acoustic emission, no obvious acoustic emission will be produced during the second pressure unless the crack produces new propagation or another reversible acoustic emission mechanism. Acoustic emission parameters of the second pressure cycle $9 \mathrm{MPa}$ boost and hold pressure are shown in figure 3 .

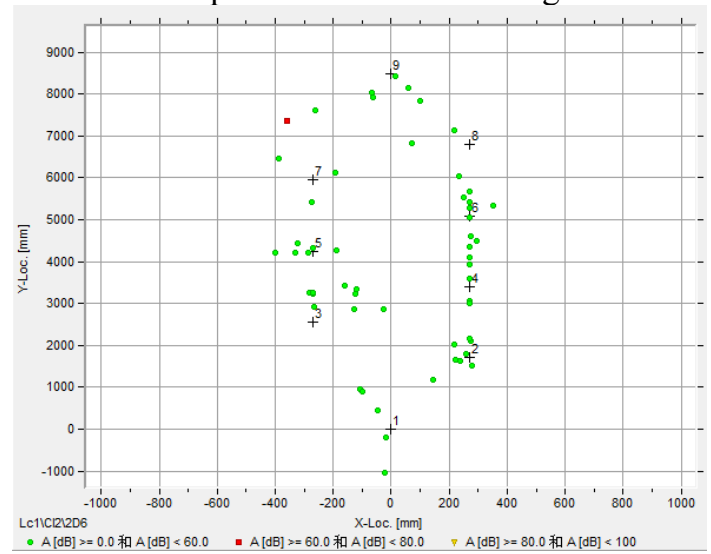

(b) Location map of crescent rib weld 


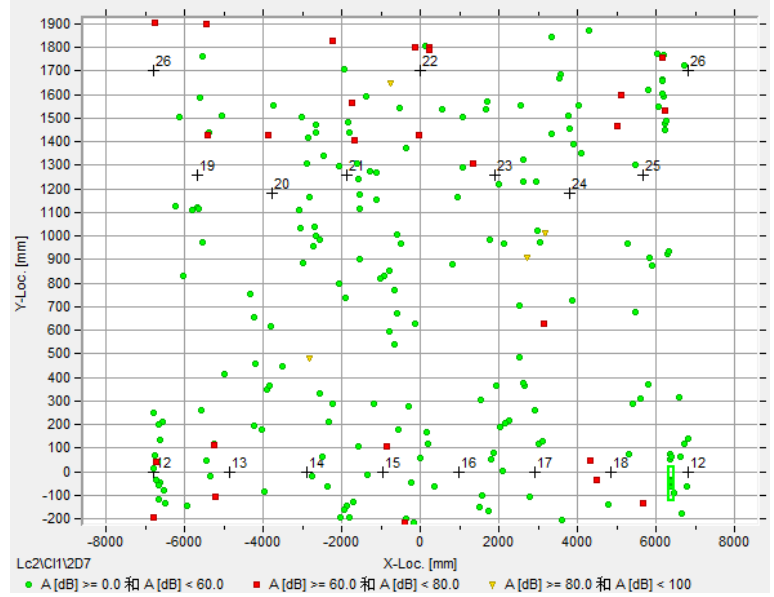

(c) Main cone circumferential weld orientation map

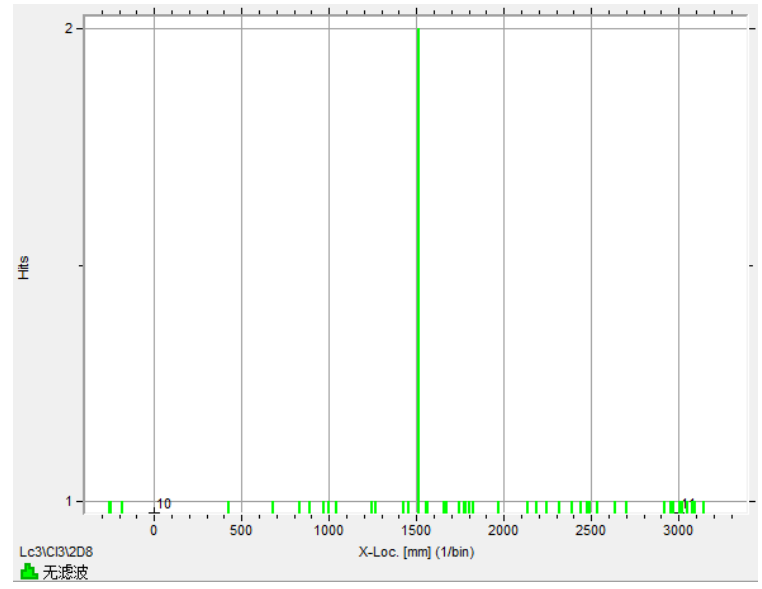

(d) Lumbar line location map of crescent ribs

Figure 3. Acoustic emission parameter diagram of the second $9 \mathrm{MPa}$ boost and hold pressure process of the $3 \#$ branch pipe

In the second pressure cycle, acoustic emission signals appear very little, and intermittent. The circular diameter of $10 \%$ of the maximum spacing of the sensor array is taken as the evaluation area, and the acoustic emission location event falling in the same evaluation area is the acoustic emission location event generated as the same source area. In the first pressure cycle, there is an acoustic emission location source in the process of boosting and keeping pressure. In the second pressure cycle, there is no acoustic emission location source. The activity grade of the acoustic emission location source is assessed as medium activity. Acoustic emission location intensity belongs to low intensity. Comprehensive assessment of II grade, no need to re-check.

In the process of hydraulic test, stress and displacement are monitored except for the acoustic emission sensor. The stress and displacement changes in the corresponding parts do not exceed the design value.

\section{Conclusion}

Acoustic emission monitoring technology has high sensitivity to crack growth monitoring and can be well positioned according to sensor arrays. As safe monitoring means of the hydraulic test of steel bifurcation pipe, it is advantageous and necessary. It can warn the dangerous situation in the process of raising pressure and keeping the pressure of hydraulic test of retaining branch pipe and ensure the safety of test effectively.

\section{Acknowledgments}

We gratefully acknowledge the Open Foundation of National Research Center on Dam Safety Engineering Technology (Nos. CX2019B03) for their support of this work.

\section{References}

1. Wang Li,Chen Peng,Zou Feifei.Changlongshan pumped storage power plant environmental cost management work is analysed.[J].YANGTZE RIVER,2019,50(S1)pp 324-326.

2. Lu Chao, Ding Peng, Chen Zhenhua. Acoustic Emission Behaviors of Carbon-cloth/epoxy Composites in Compression Test. Key Engineering Materials Vols.480-481 (2011) pp 421-426.

3. Félix Leaman; Cristián Molina Vicuña; Elisabeth Clausen.A Review of Gear Fault Diagnosis of Planetary Gearboxes Using Acoustic Emissions.Acoustics Australia (2021) PP 1-8

4. Lu Chao, Ding Peng, Chen Zhenhua. AE Signal Analysis of Carbon Fiber Reinforced Composites Based on Hilbert-Huang Transform. Advanced Materials Research Vols. 301-303 (2011) pp 447-451.

5. Zhu, L., Zou, B., Gao, S. H., Jiang, M., \& Li, Z. P. (2014). Research on Gate Valve Internal Leakage Detection Based on Acoustic Emission Signal Processing. Advanced Materials Research, 1037, pp 169-173.

6. Eberhardt E, Stead D, Stimpson B, et al. Quantifying progressive pre-peak brittle fracture damage in rock during uniaxial compression[J]. International Journal of Rock Mechanics and Mining Sciences, 1999, 36(3): 361-380.

7. Ohno K, Ohtsu M. Crack classification in concrete based on acoustic emission[J]. Construction and Building Materials, 2010, 24(12): 2339-2346.

8. David, Rao R B. Development of Acoustic Emission Technology for Condition Monitoring andDiagnosis of Rotating Machines; Bearings, Pumps, Gearboxes, Engines and RotatingStructures.[J]. The Shock and Vibration Digest, 2006, 38(1): 3-16. 
9. P. Mazal, F. Vlasic, V. Koula,Use of Acoustic Emission Method for Identification of Fatigue Microcracks Creation,Procedia Engineering,Volume 133,2015,PP379-388.

10. A. Behnia, H. K. Chai, and T. Shiotani, "Advanced structural health monitoring of concrete structures with the aid of acoustic emission," Construction and Building Materials, vol. 65, pp. 282-302, 2014. 